\title{
Giant Lipoma in the Thenar Eminence: Report of 2 Cases and Literature Overview
}

\author{
Oscar A. Mora-Torres ${ }^{1 *}$, Isaac Shturman-Sirota ${ }^{2}$, Jorge A. Abello-Vaamonde ${ }^{3}$, Irving K. \\ Moreno-Valladares ${ }^{4}$, Alberto Robles-Méndez-Hernández ${ }^{5}$, Fernando E. Fuentes-Muñoz ${ }^{6}$ \\ ${ }^{1}$ Department of General Surgery, Angeles Lomas Hospital. Huixquilucan; State of Mexico, Mexico. \\ ${ }^{2}$ Specialist in Hand Surgery and Facial Rejuvenation. Department of Plastic Aesthetics and Reconstructive \\ Surgery, Angeles Lomas Hospital; State of Mexico, Mexico. \\ ${ }^{3}$ Department of General Surgery, Angeles Lomas Hospital. Huixquilucan; State of Mexico, Mexico. \\ ${ }^{4}$ Department of General Surgery, San Angel Inn Hospital; Mexico City, Mexico. \\ ${ }^{5}$ Department of General Surgery, Angeles Metropolitano Hospital, Mexico City, Mexico. \\ ${ }^{6}$ Faculty of Medicine, Anahuac Mexico University; Naucalpan de Juarez, Mexico.
}

*Corresponding Author: Oscar A. Mora-Torres, MD, Department of General Surgery, Angeles Lomas Hospital. Huixquilucan; State of Mexico, Mexico. 52787, Email: Alejandromora118@gmail.com

\begin{abstract}
Lipomas, subcutaneous tumors of adipose tissue, are the most common benign neoplasms of mesenchymal origin in adulthood, with an incidence of 1 in 1,000 people. Approximately 25\% present in any of the upper extremities; however, it is very rare to find them on the palms of the hands, especially when they measure more than 5 centimeters in diameter. By complying with this last morphological characteristic, they qualify as "giant lipomas", and merit a focused diagnostic-therapeutic approach, regarding neurovascular or musculoskeletal complications and the possibility of malignancy in the differential diagnosis of their clinical presentation.
\end{abstract}

Keywords: Lipoma, Neoplasms, Connective Tissue, Plastic Surgery, Hand.

\section{INTRODUCTION}

In this manuscript we report the diagnostic and therapeutic approach of two patients with superficial giant lipomas over the thenar eminence. Both tumors developed following the typical pattern described by literature: slowly growing, mobile, soft, and painless masses, exceeding 5 centimeters in diameter. Each example corresponds to each of the possible locations of deep lipomas of the hand over the thenar eminence: on the synovial sheath of the flexor apparatus -epivaginal-, or under it endovaginal-. Their size was sufficient to cause functional impairment and constant pain, so surgical excisions were performed preserving local neurovascular structures. During the follow-up period only one patient suffered neurological sequela.

\section{CASE\#1}

A 65-year-old female patient, presented with an 8-year history of a smooth, nontender and slowly growing tumor over the thenar region of her right hand. It's initial description highlighted a diameter of 0.5 centimeters, but over the years expanded up to 6 centimeters. The patient referred local, deep discomfort which gradually aggravated to moderate intensity as tumor sized increased, accompanied with progressive compromise of hand functionality. Upon physical examination, besides documenting the previously described morphologic parameters of the tumor, the authors evidenced the patient had reduced grip strength and limited fine pinch in the affected hand. Taking into consideration the characteristics of the tumor and its pattern of development, a clinical diagnosis of giant lipoma was made without need of magnetic resonance imaging evidence. 


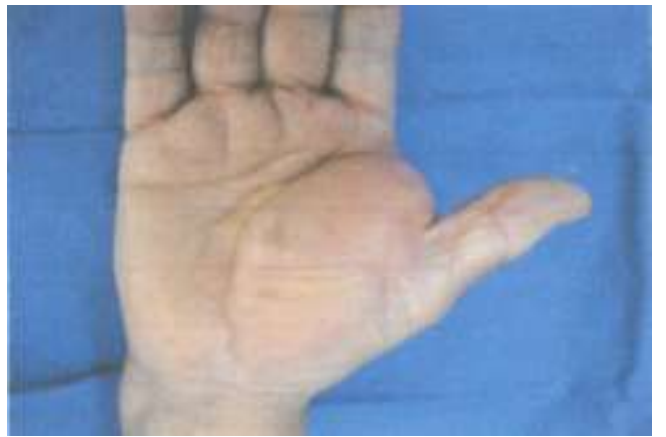

Figure1. Giant lipoma ( $6 \times 5 \times 3$ centimeters) over the thenar region of the right hand of patient \#1

The patient underwent surgery under regional anesthesia. The authors performed a median nerve truncal block at the level of the wrist, with lidocaine and epinephrine 1: 200,000. Ischemia was achieved using an eSmarch bandage. A thenar longitudinal access incision was made, exposing an encapsulated adipose mass located with an upper limit distally displacing 2.5 centimeters the commissure of the first interdigital space, with a lower limit at the level of the carpometacarpal joint of the first and second fingers, radial at the level of the pulley A1 of the thumb and ulnar at the level of the third metacarpal. The tumor was in a plane under the neurovascular elements, which showed evident elongation and overlying displacement, and adhered to the muscular fascia of the two heads of the adductor pollicis, first dorsal interosseous and first lumbrical, as well as to the sheath of the flexors of the second finger. There was no evidence of muscular or neurovascular infiltration.

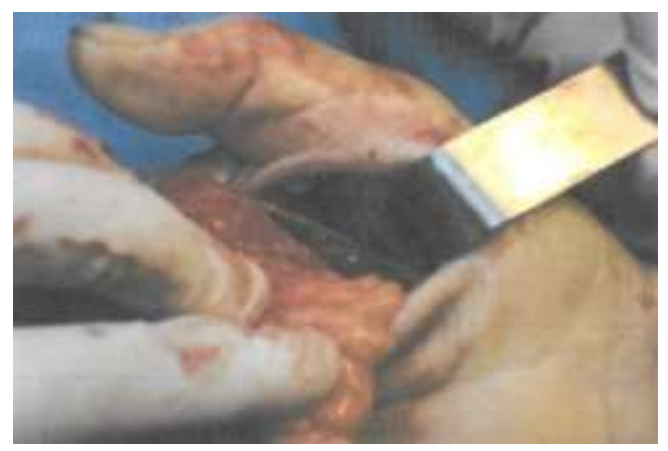

Figure2. Thenar longitudinal access exposing the tumor on patient \#1

Complete dissection of the tumor was performed, in $360^{\circ}$ and in a single block. The excised mass measured $6 \times 5 \times 3$ centimeters. The first, second and third branches of the median nerve were found to be elongated, with approximately 2-3 centimeters of redundancy, as well as the corresponding vascular structures. At the end of the procedure, hemostasis without ischemia was verified, as well as muscular and neurovascular integrity. No repair was necessary. Subsequent histopathologic evaluation revealed no evidence of liposarcoma.

During the postoperative period, the patient reported a zone of dysesthesia of 1 centimeter of diameter in the external portion of the thenar region that progressively diminished. After 8 months of follow-up, there has been no recurrence of the tumor, complications, or motor sequelae; complete functional recovery and absolute remission of pain are reported.

\section{CASE \#2}

A 67-year-old female patient presented with a 10-year history of a smooth, nontender and slowly growing tumor over the thenar eminence of her right hand. Although no discomfort was initially noticed, pain, motor dysfunction and dysesthesia of the thumb developed as the mass progressively grew to a maximum of $8 \mathrm{~cm}$ of diameter. After the patient was clinically diagnosed with a giant lipoma, surgical excision was performed. During the procedure, an encapsulated adipose mass of $15 \times 8$ centimeters located with an upper limit distally displacing the commissure of the first interdigital space by 4 centimeters, with a lower limit at the level of the carpometacarpal joint of the first and second fingers, radial at the level of the radial border of the first metacarpal, and ulnar at the level of the third metacarpal. After complete excision, histopathologic evaluation ruled out the diagnosis of liposarcoma. 
During the postoperative period, no tumor recurrence nor sequelae occurred; complete functional recovery and absolute remission of pain were reported by the patient.

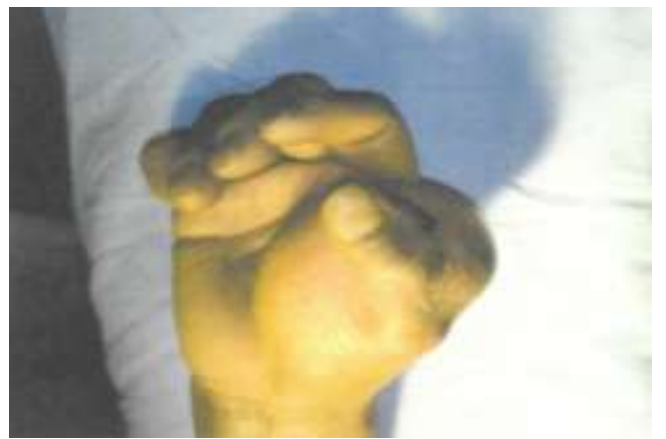

Figure3. Giant lipoma (15 x 8 centimeters) over the thenar region of the right hand of patient \#2

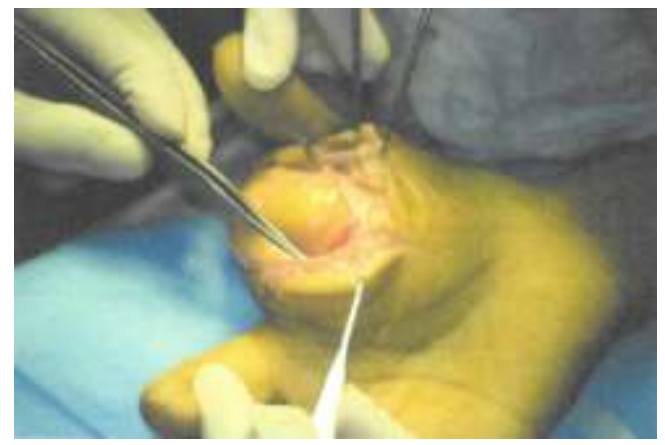

Figure4.Thenar longitudinal access exposing the tumor on patient \#2

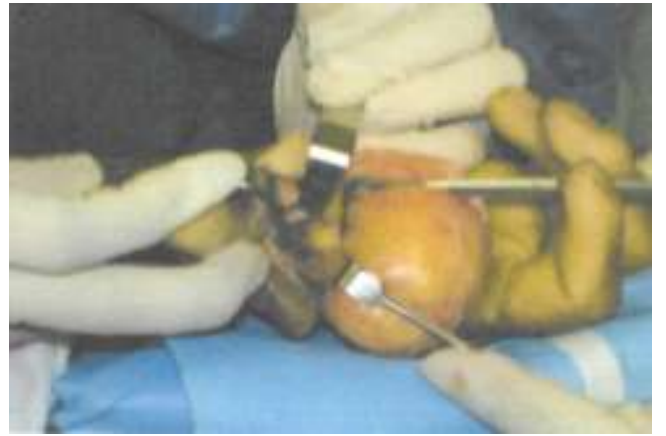

Figure5. Surgical dissection of the tumor on patient \#2

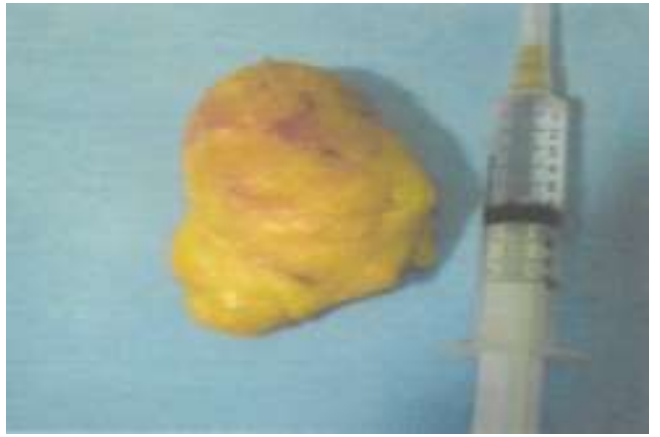

Figure6. Gross pathology: completely dissected giant lipoma of the thenar region of the hand of patient \#2

\section{DISCUSSION}

Lipomas are the most common benign tumors of mesenchymal origin in the adult population, presenting more frequently in male patients, mainly between the fourth and sixth decade of life. [22] 11.5 - 27\% develop in the upper extremities, [12] representing 5\% and $1-3.8 \%$ of benign tumors of the upper extremities and of the hand, respectively. [13] The latter are classified as endovaginal and epivaginal according to their relationship with the synovial sheath of the flexor apparatus. [14] Likewise, 
superficial lipomas are located in the subcutaneous tissues, while deep ones, more frequent than the previous ones, are in the Guyon canal, in the carpal tunnel or below the palmar fascia. [11]

Lipomas generally appear as solitary tumors, but between $5 \%$ and $10 \%$ of cases, multiple lipomas grow simultaneously, a phenomenon associated with genetic disorders such as Cowden [19], Bannayan-Zonana [20] and Proteus [21] syndromes, among others. In most cases they manifest as masses of mature adipose tissue, lobulated and lined by fibrous tissue, painless, mobile, soft, and slow growing, located in the subcutaneous tissue of the trunk or neck. However, they can also develop at the subfacial, intramural, intermuscular, interosseous, and visceral levels. [1] [2] [11] Regularly, they reach a maximum diameter of 2 to 3 centimeters without causing symptoms. In the unusual case they exceed 5 centimeters in diameter, they are referred to as "giant lipomas". These are associated with both cosmetic deformities and pain; paresthesias and/or dysesthesias occur if mass effect compromises adjacent nervous structures. Compartment syndromes related to these over-sized tumors have also been described. [3] It is important to note that some authors, such as Sánchez et. al [4] define the giant lipoma as "a lesion with more than 10 centimeters in a single dimension or more than 1,000 grams in weight".

This pathological variant is especially rare when it occurs in any of the regions of the palm of the hand. In most cases, the clinical diagnosis is sufficient, but if uncertain, imaging studies are used to corroborate the suspicion. When subjected to magnetic resonance imaging (MRI), the study of choice, lipomas appear as a homogeneous and isointense lesion of the fatty tissue in all sequences. [5] [6] [7] Among the differential diagnoses, liposarcomas, spindle cell lipomas, hibernomas, angiolipomas and atypical lipomas stand out. The treatment of asymptomatic cases is based on observation; however, symptomatic cases can be surgically resected. [8] The dead space created after dissection of a giant lipoma is usually drained using a suction drain to prevent bruising or seroma formation. Liposuction, endoscopic excision, mesotherapy and infiltrations with intralesional phosphatidylcholine have also been described as therapeutic alternatives, as long as the malignant potential of the tissue has been ruled out; however, surgical excision remains the gold standard in lipoma treatment. [11] [16] [17] Cases in which tumoral nerve infiltration does not allow its resection due to the risk of permanent nerve damage, division of the flexor retinaculum without tumor excision is recommended to relieve symptoms. [18] Postsurgical sequela, such as zones of dysesthesia, paresthesias and functional impairment, are probably associated with elongation of the median nerve due to compression of the tumor and mechanical manipulation during surgery.

\section{CONClusion}

Lipoma, the most common benign tumor of the connective tissue in adulthood, rarely occurs on the palm of the hand with a diameter greater than 5 centimeters. In this region, the protocol for studying a soft, mobile, painless, and progressively growing mass should consider lipomas and liposarcomas as differential diagnoses. Given abnormal ultrasound findings, it is useful but not essential to complement the study protocol with an MRI. Histopathological analysis may confirm the suspicion and rule out liposarcoma. Once the diagnosis has been established, in the presence of nerve and motor involvement in the limb, surgical excision of the mass is the indicated treatment. The reported cases show that this procedure ensures good results for functional recovery, as long as the lipomas are treated surgically, preserving the integrity of the neurovascular and musculoskeletal structures.

\section{FinANCIAL Disclosure Statement}

No funds were received or utilized for the research reported in this article. Dr. MoraTorres, Dr. Shturman-Sirota. Abello-Vaamonde, Dr.Moreno-Valladares, Dr. Robles-MéndezHernández and Dr. Fuentes-Muñoz have no financial interests to declare in relation to the content of this article.

\section{REFERENCES}

[1] Adipocytic tumours, in Fletcher CDM, Bridge JA, Gofendoorn PCW, Mertens F, eds: WHO Classification of Tumours of Soft Tissue and Bone, ed 4. Herndon, VA, Stylus Publishing, 2013, pp 19-42.

[2] Benign lipomatous tumors, in Goldblum JR, Folpe AL, Weiss WS, eds: Enzinger\& Weiss's Soft Tissue Tumors, ed 6. Philadelphia, PA, Elsevier, 2014, pp 443-483.

[3] Higgs PE, Young VL, Schuster R, Wedes PM. Giant lipomas of the hand and forearm. South Med J 1993;86:887-90. 
[4] Sanchez MR, Golomb FM, Moy JA, Potozkin JR. Giant lipoma: Case report and review of the literature. J Am Acad Dermatol. 1993;28:266.

[5] Murphy MD, Carroll JF, Flemming DJ, Pope TL, Gannon FH, Kransdork MJ: From the archives of the AFIP:Benign musculoskeletal lipomatous lesions. Radiographics 2004;24: 1433-1466

[6] Meyerson JL, Scharschmidt TJ, Lewis VO, Morris CD: Diagnosis and management of soft tissue masses. J Am AcadOrthop Surg 2014;22:742-750

[7] Papp BDF, Khanna AJ, Mccarthy EF, et al: Magnetic resonance imaging of soft-tissue tumors: Determinate and indeterminate lesions. J Bone Joint Surg Am 2007; 89(suppl 3):103-115

[8] Johnson C, Ha A, Chen E, Davidson D. Lipomatous Soft-tissue Tumors. Journal of the American Academy of Orthopaedic Surgeons. 2018;26(22):779-788.

[9] Wittig JC, Simpson BM, Bickels J, KellarGraney KL, Malawer MM. Giant cell tumor of the hand: superior results with curettage, cryosurgery, and cementation. J Hand Surg [Am] 2001; 26: 546-55.

[10] Athanasian EA. Malignant bone and soft-tissue sarcomas of the hand. J Am Soc Surg Hand 2004; 4: 60-72.

[11] Nieto r., luis e., \& carlos ortiz. "Lipoma gigante en mano. Reporte de caso." Revista Colombiana de Cirugía Plástica y Reconstructiva [en línea], 26.1 (2020): s. P. Web. 16 mar. 2021

[12] Glicenstein J et al (1988) Lipomes. Tumeurs de la main. Springer-Verlag, Berlin, pp 78-83

[13] Bogumill GP (1975) Tumours of the hand. Clin Orthop 108:214-222
[14] Inaparthy P, Southgate GW. Giant lipoma of hand: a case report. Eur J Orthop Surg Traumatol2006;16:251-52.

[15] Decrouy-Duruz V, Kalbermatten D, Honigmann P. Giant lipoma of the thumb. European Journal of Plastic Surgery. 2012;36(5):331-334.

[16] Bagatur AE, Yalcinkaya M. Unilateral carpal tunnel syndrome caused by an occult palmar lipoma. Ortho- pedics. 2009;32(10). pii: orthosupersite.com/view.asp?rID=43775. doi: 10.3928/01477447-20090818-20.

[17] Phalen GS, Kendrick JI, Rodriguez JM. Lipomas of the upper extremity: a series of fifteen tumors in the hand and wrist and six tumors causing nerve compression. Am J Surg. 1971;121(3):298-306.

[18] Friedlander HL, Rosenberg NJ, Graubard DJ. Intraneural lipoma of the median nerve. Report of two cases and review of the literature. $J$ Bone Joint Surg Am. 1969;51(2):352-62

[19] Weary PE, Gorlin RJ, Gentry WC, Jr, Comer JE, Greer KE. Multiple hamartoma syndrome (Cowden's disease). Arch Dermatol. 1972;106(5):682-90.

[20] Bannayan GA. Lipomatosis, angiomatosis, and macrencephalia. a previously undescribed congenital syndrome. Arch Pathol. 1971;92(1):1-5.

[21] Clark RD, Donnai D, Rogers J, Cooper J, Baraitser M. Proteus syndrome: an expanded phenotype. Am J Med Genet. 1987;27(1):99117.

[22] Rydholm A, Berg NO. Size, site and clinical incidence of lipoma. Factors in the differential diagnosis of lipoma and sarcoma. Acta OrthopScand 1983; 54:139-143.

Citation: Oscar A. Mora-Torres, Isaac Shturman-Sirota, Jorge A. Abello-Vaamonde, Irving K. MorenoValladares, Alberto Robles-Méndez-Hernández, Fernando E. Fuentes-Muñoz. "Giant Lipoma in the Thenar Eminence: Report of 2 Cases and Literature Overview". ARC Journal of Surgery. 2021; 7(2):28-32. DOI:https://doi.org/ 10.20431/2455-572X.0702004.

Copyright: (C) 2021 Authors. This is an open-access article distributed under the terms of the Creative Commons Attribution License, which permits unrestricted use, distribution, and reproduction in any medium, provided the original author and source are credited. 